\title{
Dos pliegos burgaleses: la transmisión de la "Exclamación y querella de la gobernación" de Gómez Manrique y cuatro romances del rey don Rodrigo
}

\author{
Sara RUSSO \\ Universidad Complutense de Madrid \\ sararusso@ucm.es
}

\begin{abstract}
RESUMEN
Este estudio se centra en los dos pliegos sueltos burgaleses RMND 674 y RMND 673. Después de una breve alusión a los grabados que los encabezan, considero los cinco poemas contenidos en ambos pliegos — su contenido es idéntico-y el posible significado que esta selección de obras — con mucha probabilidad nada casual— podía ofrecer al lector. Tras mencionar la hipótesis de cierta relación entre la impresión de los pliegos y el periodo histórico en el que esta se lleva a cabo me detengo en el análisis de la transmisión de los poemas. Examino las relaciones entre los dos pliegos sueltos, señalo el vínculo de los romances impresos en RMND 674 con el Cancionero de romances sin año impreso en Amberes y la utilización del Cancionero general de Hernando del Castillo como fuente del poema de Gómez Manrique.
\end{abstract}

Palabras clave: pliegos sueltos, romances, Gómez Manrique, transmisión.

\begin{abstract}
This study focuses on the two chap-books from Burgos RMND 674 and RMND 673. After a brief mention to the engravings that lead the poems, I will review the five poems included in the two chap-books (both print the same ones) and the possible meaning that this selection of works - all but accidental - could have for the reader. After considering the probable relation between the printing of the chap-books and the historical period in which it was carried out, I will analyze the transmission of the poems. I will examine the relations between the chap-books, highlighting the bond of the printed romances in the RMND 674 with the undated Cancionero de romances of Amberes and the use of the Cancionero general by Hernando de Castillo as the source of the poem of Gómez Manrique.
\end{abstract}

Keywords: chap-book, romances, Gómez Manrique, transmission. 
El punto de partida de mis investigaciones son dos pliegos sueltos que se imprimieron, sin indicaciones tipográficas, en la segunda mitad del siglo XVI en la imprenta burgalesa de Juan de Junta, como las investigaciones de la profesora Mercedes Fernández Valladares han podido confirmar ${ }^{1}$. El primero de ellos, RMND 674, vio la luz en 1550, mientras que el segundo, RMND 673, fue impreso aproximadamente entre 1565 y 1570 cuando la imprenta burgalesa ya había pasado a manos del hijo de Juan de Junta, Felipe de Junta ${ }^{2}$.

Ambos pliegos presentan exactamente las mismas obras en el mismo orden y su puesta en página también es casi idéntica; la diferencia más relevante entre los dos pliegos es el grabado que los encabeza. El grabado xilográfico que encabeza RMND 674

[...] representa un combate ecuestre entre dos caballeros armados con lanzas, que es presenciado por damas y galanes desde la galería de un palacio y, como fondo una marina con un navío y un castillo, dentro de un marco de doble filete. Aparece rodeado por una orla abierta por debajo, formada por adornitos tipográficos en espiral. ${ }^{3}$

Sin embargo el grabado que encabeza RMND 673 va "rodeado por una orla formada por cuatro piezas xil." y "representa el ataque a una ciudad amurallada, dentro de un marco de doble filete".

Hay que considerar, como bien afirma Di Stefano, que "el posible atractivo exterior del pliego suelto se juega todo en su portada"; es decir, el grabado que encabeza estos dos pliegos sueltos con mucha probabilidad no solo no fue elegido al

\footnotetext{
${ }^{1}$ M. Fernández Valladares (2005), v. 2, pp. 885 y 1102. Antes de Fernández Valladares, durante los años 30 del siglo pasado, Rafael Lapesa llevó a cabo un proyecto de catalogación de pliegos sueltos de romances todavía inédito. A este propósito le agradezco infinitamente al profesor Antonio Cid Martínez la ayuda que me ha proporcionado y el haberme permitido acceder a la Fundación Ramón Menéndez Pidal para consultar los fondos en ella contenidos entre los cuales se encuentra el mencionado trabajo de Lapesa. En su catálogo, el estudioso, en un riguroso orden cronológico, proporciona una descripción de los pliegos indicando su ubicación y en el caso de los pliegos sine notis, apunta la fecha de impresión y el taller de imprenta donde esta se llevó a cabo. En el caso específico de los pliegos objeto de mi estudio (RMND 674 y RMND 673) solo describe el más antiguo de los dos (RMND 674), ya que su catálogo llega hasta los años 50 y RMND 673 se imprimió entre 1565-1570. De RMND 674 Lapesa apunta lo siguiente: "[Burgos, Juan de Junta] 1550 ".

${ }^{2}$ Utilizo, para referirme a los piegos sueltos, el número que corresponde a cada pliego en A. Rodríguez-Moñino (1997). Precede al número la sigla de la obra de Rodríguez-Moñino mencionada.

${ }^{3}$ M. Fernández Valladares (2005), v. 2, p. 886.

${ }^{4}$ M. Fernández Valladares (2005), v. 2, p. 1102.
} 
azar, sino que incluso fue utilizado para remitir de alguna manera a un cierto "código iconográfico" bien presente en el público lector".

Los cuatro romances con los que comienzan los pliegos pertenecen al ciclo del rey don Rodrigo:

- El primero, "Don Rodrigo rey de España", trata de la entrada del rey en la casa de Hércules.

- En el segundo, "Las huestes de don Rodrigo", se relata el abandono de la batalla por parte del rey.

- En el tercero, "Ya se sale de la priessa", narra la derrota del rey y el lamento de su esposa.

- El cuarto romance, "Después quel rey don Rodrigo", trata de la penitencia de este.

Los pliegos se cierran con el poema de Gómez Manrique: "Quando Roma conquistava", también conocido como "Exclamación y querella de la gobernación",

Una primera lectura inevitablemente lleva a la pregunta de si a la reunión de estos cinco poemas en el mismo pliego subyace algún tipo de criterio temático. Por eso mismo, recordemos que la figura del rey don Rodrigo pasó a la historia —sobre todo debido a la leyenda surgida a su alrededor - como el rey que, aprovechándose de la hija de don Julián, conde de Ceuta, hizo que este se vengara apoyando la entrada y consiguiente invasión musulmana en la península ibérica en 711. La obra de Gómez Manrique, a su vez, repite a lo largo de sus estrofas el conocido tópico del mundo al revés a través de la enumeración de actitudes y valores humanos invertidos que bien reflejan la confusión en la que está sumida la sociedad cuando esta se fundamenta sobre un mal gobierno. ¿Puede considerarse la obra manriqueña una suerte de compendio y explícita amonestación al comportamiento del rey don Rodrigo?

${ }^{5}$ Ambos grabados fueron utilizados varias veces en la imprenta burgalesa para ilustrar exclusivamente pliegos de romances. La excepción es el grabado que encabeza RMND 674 que, en una sola ocasión, ilustra una obra en prosa, el Libro de los siete sabios de Roma. Una rápida ojeada a la relación de apariciones de los grabados de ambos pliegos (agradezco a la profesora Mercedes Fernández Valladares que me haya proporcionado estas informaciones extraídas de su Repertorio digital de materiales iconográficos y tipográficos de la imprenta en Burgos (s. XVI), en preparación) no hace sino afianzar las palabras de Di Stefano que considera que el grabado ofrecido por los pliegos sueltos se caracterizaba por una convencionalidad "en sí misma evocadora, por encima de la congruencia con el texto, porque remitía - como mínimo- a una situación, a un género, a un código iconográfico”. G. Di Stefano (2000), p. 172.

${ }^{6}$ Sobre la obra de Gómez Manrique véase la edición de Vidal González, G. Manrique (2003). El tema romancístico del rey don Rodrigo ha sido tratado en varias ocasiones por diferentes estudiosos, no obstante, la obra de Menéndez Pidal sigue representado el punto de partida sobre este argumento, Romancero tradicional de las lenguas hispánicas (1957). 
Un razonamiento de este tipo conllevaría suponer que en las imprentas existía una persona encargada de elegir las composiciones para un pliego y decidir el criterio para ello. Infantes, esquematizando la evolución del género editorial del pliego suelto desde la etapa incunable hasta finales del siglo XVI, indica que "el aumento de la producción [de pliegos sueltos] una vez asentadas su presencia y su oferta editorial y [...] la casi exclusividad de determinados centros editoriales (y culturales) de producción" apuntan a la existencia de una "estrategia [...] más calculada y premeditada de lo que parece"”. En la primera mitad del siglo XVI, a través del pliego suelto se ofrecía a un público de pocos recursos económicos lo que Infantes denomina

los conjuntos: poesía derivada del Cancionero, poesía tradicional, romancero, etc.; nace la literatura de consumo popular: pronósticos, relaciones, etc.; pero, sobre todo nace la noción del espacio tipográfico y todo un entramado comercial y editorial que se apoya el los pliegos sueltos (y los libros de cordel) para ganarse un público fiel con una literatura específica coherentemente programada. ${ }^{8}$

El impresor de pliegos sueltos eligía así un tipo de "literatura exclusiva y menor" "que con su extensión condicionaba la del mismo pliego y que, posiblemente, derivaba de agrupaciones previas ${ }^{10}$.

En el caso específico de pliegos de romances, en los estudios del profesor Giuseppe Di Stefano se subraya la intencionalidad en la base de la elección de estos para un mismo pliego: "L'accostamento dei romances tra loro è invece molte volte tutt'altro che casuale. Un pliego a componenti plurime costituisce un macrotesto che indirizza la lettura dei singoli pezzi in modi diversi, piú o meno stringenti ed espliciti". ${ }^{11}$ A pesar de que Di Stefano no manifieste en ningún momento quién se encargaba de la elección de los poemas para un mismo pliego ni si esta se llevaba a cabo dentro o fuera del taller, en una ocasión menciona que quizás se debía a la iniciativa del impresor ${ }^{12}$. Apunta que "L'incontro di testi diventa chiave di lettura e al medesimo tempo segno di un modello di cultura e di gusto"13 de manera mucho

\footnotetext{
${ }^{7}$ V. Infantes (1988), p. 246.

${ }^{8}$ V. Infantes (1988), p. 247.

${ }^{9}$ V. Infantes (1889), p. 88.

${ }^{10}$ A. Rodríguez-Moñino (1997), p.15. Norton y Wilson señalan, por ejemplo, la utilización del Cancionero general de Del Castillo y del Cancionero de todas las obras de Juan del Enzina como fuente para material para pliegos sueltos. F. J. Norton y E. M. Wilson (1969), p. 9.

${ }^{11}$ G. Di Stefano (1982), p. 213. Mario Garvin también sostiene esta idea subrayando el "mensaje supratextual" que confiere el orden de aparición de los romances dentro de un mismo pliego. M. Garvin (2006), p. 492.

${ }^{12}$ G. Di Stefano (1971), p. 133.

${ }^{13}$ G. Di Stefano (1982), p. 213.
} 
más marcada y explícita que en los Cancioneros de romances de la mitad del siglo XVI, de los que muchos pliegos derivan.

Mientras que en el caso de los cuatro romances del rey don Rodrigo sí existieron agrupaciones previas que los reunían tal y como aparecen en los pliegos de los que me ocupo, no se puede afirmar lo mismo en el caso del poema de Gómez Manrique. No nos ha llegado ninguna recopilación que reúna los cuatro romances junto a la "Exclamación y querella de la gobernación". Me inclino a no considerar la elección de este último poema para su impresión en el pliego como una mera casualidad, ya que la temática encaja perfectamente con la de los romances y su colocación al final del pliego, como ya apunté anteriormente, parece resumir y evidenciar al mismo tiempo las consecuencias de un comportamiento disoluto en un soberano.

De todos modos, hay que considerar que se dan varios casos de pliegos de romances que recogen en sus últimos folios una obra procedente de algún cancionero. Respondía esta práctica no solo al gusto de la época, sino también a necesidades de tipo práctico, ya que se intentaba rellenar el pliego de modo que apenas quedara espacio vacío. Así que, puede que la obra de Gómez Manrique sea meramente un poema insertado en el pliego suelto a modo de relleno, para no desaprovechar los últimos folios que, sin ella, quedarían en blanco. Sin embargo, y desde este punto de vista práctico, a pesar de la inserción de la "Exclamación y querella de la gobernación" el vuelto del último folio sigue presentando una gran porción de espacio en blanco. En el caso de RMND 674, el espacio en blanco se corresponde a la mitad del folio y a dos tercios en RMND 673. Puestos a elegir y dado que, como se verá más adelante en este mismo trabajo, la fuente de la obra de Gómez Manrique para este pliego es el Cancionero general de Hernando del Castillo, la elección de la obra de relleno habría podido recaer en un poema más largo para aprovechar por completo el vuelto del último folio.

$\mathrm{Si}$ aceptamos que la reunión de estos cinco poemas en un mismo pliego fue deliberada y que respondió a criterios temáticos, sigue siendo una incógnita a quién se debió tal elección. De todos modos, las posibilidades de que esta selección se llevara a cabo dentro del taller de Juan de Junta, desde mi punto de vista, son elevadas.

Antes de seguir con el análisis de la transmisión de los textos contenidos en los dos pliegos, considero interesante reflexionar sobre otro aspecto relativo al mensaje implícito que la selección de poemas contenidos en RMND 674 y 673 puede implicar. ¿La impresión de estos pliegos sueltos en estos años concretos - RMND 674 en 1550 y RMND 673 en 1565-70 - tiene algún tipo de relación con el periodo histórico en que se efectúa? Es decir, ¿el mensaje implícito derivado del conjunto de obras publicadas en los pliegos tenía algún tipo de relación con la historia de España en aquella época?

En este caso también es preciso proceder con cierta cautela, ya que ello implicaría afirmar que alguien dentro de la imprenta decidió imprimir estos pliegos 
a modo de crítica velada hacia el reinado de Carlos I de España —en el caso de RMND 674- y de Felipe II —on el caso de RMND 673-. A la vez, podría entenderse el contenido de los dos pliegos como una suerte de advertencia que, a través del ejemplo del rey don Rodrigo, rematado por la obra de Gómez Manrique, sugiere los comportamientos que todo monarca tendría que evitar. Es esta segunda hipótesis la más probable, ya que, así, el mensaje del pliego tendría un alcance más vasto y universal configurándose como exemplum. Recordemos que, mientras que en los primeros tiempos de la imprenta manual se buscaba el mecenazgo de diferentes estamentos para financiar la impresión de obras a veces muy caras, con el paso del tiempo y en el caso específico de los pliegos sueltos, los impresores aprovecharon la posibilidad de dirigirse a un público de reducida capacidad económica con unas obras producidas a bajo coste caracterizadas por el "despego del mecenazgo" y el "olvido de los compromisos oficialistas"

Juan de Junta, a la hora de preparar el modelo de composición para el pliego más antiguo, RMND 674, el que se imprimió en 1550, tuvo que tener delante material de lo más variado. A la hora de recopilar el poema de Gómez Manrique, la "Exclamación y querella de la gobernación" para su impresión, se sirvió del Cancionero general de Hernando del Castillo y, específicamente, de una edición posterior a la primera.

El decir manriqueño se compone de dieciocho estrofas; sin embargo, solo la primera edición del Cancionero general de 1511 recoge el poema íntegramente. A partir de la segunda edición, de 1514, todas las demás reproducen la laguna de la estrofa que empieza con el verso "Es peligro navegar...". El pliego suelto burgalés RMND 674 reproduce, a su vez, la laguna, evidenciando de esta manera la relación que se da entre 14CG o cualquiera de las demás ediciones de Hernando del Castillo precedentes a la impresión del pliego en 1550 y el mismo pliego (RMND 674).

Por la fecha de edición del pliego es probable que fuera la obra de Hernando del Castillo la que sirviera de modelo para el pliego, transmitiéndole la laguna. Sin embargo, tiene que considerarse también que bien pudo ser que el poema circulara mútilo a través de otro medio, que hoy en día no nos ha llegado, y que este sirviera de fuente para el pliego. De todos modos, me inclino más por la primera de estas dos hipótesis. Además, en varias ocasiones se ha subrayado la gran importancia del Cancionero general en el mercado editorial de las primeras décadas del siglo XVI y su utilización como fuente de material poético para pliegos sueltos ${ }^{15}$.

Empleando como testimonios base $14 \mathrm{CG}$, por ser el primero que recoge la laguna, y 40CG, por ser la edición anterior a la publicación de RMND 674, se puede

\footnotetext{
${ }^{14}$ V. Infantes (1989), p. 88. Véase también V. Beltrán (2006).

${ }^{15}$ Han tratado este tema, entre otros, L. Puerto Moro (2012), F. J. Norton, E. M. Wilson (1969), Rodríguez-Moñino en su edición del Cancionero general recopilado por Hernando del Castillo (1958), G. Di Stefano (1971), V. Infantes (1988).
} 
apreciar cómo las variantes de los tres testimonios impresos son principalmente innovaciones del pliego suelto con respecto a las dos ediciones del Cancionero general, todas ellas introducidas, con mucha probabilidad, en el taller burgalés donde se imprimió el pliego:

- v. 53 punen $14 C G 40 C G$ : ponen $R M N D 674$

Esta variante se deba probablemente a que RMND 674 malinterpretó el significado de los versos "do no punen maleficios / es gran locura bevir" y cometió una trivialización. En:

- v. 89 las ovejas $14 C G 40 C G$ : los ganados $R M N D 674$

Respetando el verso octosílabo, el pliego suelto introduce un sinónimo de la lectio transmitida por los otros dos testimonios y, por último:

- v. 9 en un $14 C G 40 C G$ : en el RMND 674

Se trata de una variante de muy poca importancia. En los demás casos, las lecturas de RMND 674 coinciden con 14CG y 40CG (omito en todo momento las variantes gráficas y las de lengua ${ }^{16}$ ).

En lo que concierne a los cuatro romances del ciclo del rey don Rodrigo, el primer testimonio que tenemos de esos poemas es el Cancionero de romances impreso en Amberes sin fecha, aunque su publicación se suele ubicar entre 1547$1548^{17}$. Esta obra señala el comienzo de la gran etapa de publicación de romances en el siglo XVI y, en su prólogo, el impresor Martín Nucio hace referencia a las fuentes orales y escritas que utilizó para recopilar su obra:

Puede ser que falten aquí algunos (aunque muy pocos) de los romances viejos, los cuales yo no puse o porque no han venido a mi noticia o porque no los hallé tan cumplidos y tan perfectos como quisiera, y no niego que en los que aquí van impresos habrá alguna falta, pero esta se debe imputar de los ejemplares de adonde los saqué, que estaban muy corruptos, y a la flaqueza de la memoria de algunos que me los dictaron, que no se podía acordar de ellos perfectamente. ${ }^{18}$

Por lo que atañe a las fuentes escritas del Cancionero de romances sin año, Martín Nucio tuvo que utilizar el Cancionero general de Hernando del Castillo y pliegos sueltos. La obra de Del Castillo, de todos modos, no recoge ninguno de los cuatro romances objeto de mi estudio.

${ }^{16}$ A la hora de distinguir entre variantes de lengua, gráficas y textuales me sirvo de P. Sánchez-Prieto Borja (1998).

${ }^{17}$ Sobre la fecha de publicación del Cancionero de romances sin año: Romancero (2004), p. 25; El Romancero (1983), p. 18 y Cancionero de romances impreso en Amberes sin año (1945), p. V.

${ }^{18}$ Reproduzco aquí parte del prólogo de Martín Nucio utilizando la edición del romancero de Pedro M. Piñero: Romancero (2004), p. 26. 
Como ya apunté anteriormente, los dos pliegos sueltos que nos han llegado y que recogen los cuatro romances se imprimieron con posterioridad a la publicación del Cancionero de romances sin año.

De esta manera se nos presentan tres posibilidades:

1. Existió una edición anterior de RMND 674, hoy en día perdida (excluyo de momento RMND 673), que llamaré PL (pliego perdido), que presentaba diferentes rúbricas con respecto a RMND 674 (se aclarará este punto en las próximas páginas). PL sirvió de fuente a la obra de Nucio y al mismo pliego RMND 674. Dado que varios estudios han subrayado el gran número de pliegos sueltos que se perdieron y destruyeron a lo largo de los siglos, es una hipótesis verosímil. De hecho, entre otros, Menéndez Pidal sostiene esta idea ${ }^{19}$.

2. Existió una edición anterior e idéntica de RMND 674 que sirvió como fuente al Cancionero y al mismo pliego RMND 674. Utilizo el término "idéntica" impropiamente para referirme, en esta circunstancia, a una edición que no presenta variantes relevantes con respecto a RMND 674.

3. Puede que fuera la obra de Nucio la que sirviera como fuente al pliego RMND 674.

Consideremos ahora las variantes que se dan entre el Cancionero de romances sin año y el pliego RMND 674 en cada uno de los cuatro romances para averiguar si este tipo de estudio puede ayudar a arrojar nueva luz sobre el asunto.

1. Romance: "Don Rodrigo rey de España”. En:

- v. 12 quisiessen $R M N D 674$ : quisiesse $C s a$

Csa lee correctamente ya que el sujeto es el rey don Rodrigo:
Bastecido el gran torneo, queriéndose començar, vino gente de Toledo para avelle de suplicar que a la antigua casa de Hércules quisiesse un candado hechar como sus antepassados lo solían acostumbrar.

Bien pudo deberse esta trivialización a un despiste ocurrido en el mismo taller de imprenta.

- v. 22 ha $R M N D$ 674: as $C s a$

En:

- v. 23 abra RMND 674: abraire $C s a$

Csa trivializa, mientras que el pliego lee correctamente.

\footnotetext{
${ }^{19}$ Véase a este propósito la edición de R. Menéndez Pidal: Romancero tradicional de las lenguas hispánicas (1957).
} 
- v. 36 fuera a quemar $R M N D$ 674: fuera quemar $C s a$

2. Romance: "Las huestes de don Rodrigo".

- v. 27 un cerro RMND 674: de un cerro Csa

En:

- v. 59 d'este $R M N D$ 674: de aqueste $C s a$

La variante que presenta el pliego es un ejemplo de modernización lingüística que, con mucha probabilidad, se llevó a cabo en el taller burgalés.

3. Romance: "Ya se sale de la priessa". En:

- v. 16 un capitán RMND 674: un su capitán Csa

RMND 674, suprimiendo el posesivo, presenta un verso de siete sílabas mientras que Csa permanece más fiel a la métrica octosílabica del romance ${ }^{20}$.

4. Romance: "Después que el rey Don Rodrigo".

- v. 42 valor $R M N D$ 674: valer $C s a$

- v. 61 vengo me hazer $R M N D 674$ : vengo a hazer $C s a$

- v. 84 le $R M N D$ 674: lo Csa

En:

- v. 60 yo soy el que $R M N D$ 674: yo soy que $C s a$

La lectura del pliego suelto rompe, otra vez, con el verso de ocho sílabas. Lo mismo ocurre en:

- v. 75 fue luego RMND 674: fuele luego Csa

Las variantes que acabo de mencionar no aclaran si fue el Cancionero de romances sin año el que copió PL, o sea, una edición anterior de RMND 674, como indica Menéndez Pidal, si RMND 674 copió el Cancionero o, en última instancia, si Csa copió una hipotética edición anterior e idéntica de RMND 674. Resulta difícil pensar que si PL tenía las mismas variantes hipo- e hipermétricas de RMND 674, Csa corrigiera esa fuente sistemáticamente, restableciendo el verso de ocho sílabas. Lo mismo podría decirse en el caso de la variante que moderniza el verso de "Las huestes de don Rodrigo". Mientras que en el caso contrario, el encargado de realizar la copia - teniendo delante variantes en Csa del tipo abraire del v. 23 de "Don Rodrigo rey de España"- pudo percatarse de la trivialización y corregirla.

Llegados a este punto, resulta muy significativo el análisis de las rúbricas en los dos testimonios:

${ }^{20}$ Considero inevitable apuntar que las divergencias en las lecciones de los dos testimonios pueden causar hipo- o hipermetría. Sin embargo, hay que tener en cuenta que la forma métrica del romancero siempre ha sido un tema difícil de tratar, entre otras cosas porque se ha podido constatar que la medida octosilábica del romance "no es regla fija, ya que se encuentran con frecuencia versos de siete o de nueve sílabas”. El Romancero (1983), p. 44. Véase también el capítulo que Menéndez Pidal dedica a este tema en R. Menéndez Pidal (1953). 
- Romance del rey don Rodrigo cómo entró en Toledo en la casa de Hércules Csa: omite RMND 674.

- Romance del rey don Rodrigo cómo perdió a España Csa: Romance del rey don Rodrigo RMND 674.

- Don Rodrigo cómo fuyó de la batalla Csa: Romance del rey don Rodrigo RMND 674.

- Romance de la penitencia del rey don Rodrigo Csa RMND 674.

Las primeras tres rúbricas que se omiten en el pliego suelto o se sustituyen con el más simple "Romance del rey don Rodrigo" me hacen suponer que es más probable que se haya decidido, teniendo delante el Cancionero de romances sin año, omitirlas o simplificarlas en el pliego suelto. Esta hipótesis, en mi opinión, es más probable que pensar que se innovara en el Cancionero de Amberes, creando tres rúbricas nuevas para encabezar los romances, teniendo como fuente la hipotética edición anterior e idéntica de RMND 674. Queda, así, descartada esta última hipótesis.

De todos modos, a este elemento habría que añadir también otra consideración más que quizás sirva para sostener esta idea. Anteriormente, apunté la posibilidad de que la selección de obras que tenía que imprimirse en un pliego suelto quizás derivara de agrupaciones previas y no de la voluntad de alguien dentro del taller tipográfico. Así que, bien puede ser que la agrupación previa que sirve de modelo a RMND 674 sea el mismo Cancionero de romances sin año que, efectivamente, recoge solo estos cuatro romances del ciclo del rey don Rodrigo y los ordena en la misma secuencia que RMND 674.

Hay que considerar también una última posibilidad en lo que concierne a las rúbricas. Puede ser que Csa tuviera delante PL y que este pliego recogiera las rubricas tal como se leen en Csa. De este modo, Csa sería el que copia PL y, a su vez, RMND 674 también utilizaría PL como fuente, simplificando sus rúbricas u omitiéndolas.

Examinando la portada de RMND 674, se observa que el pliego empieza: "Aquí comiençan quatro romances del rey Don Rodrigo. Con una obra de Gómez Manrique. Agora nuevamente impressos." El hecho de que se especifique que los romances y el poema manriqueño están "nuevamente impressos" implica que hubo una impresión anterior de las cinco obras. Por tanto, esta indicación descartaría que la impresión anterior de RMND 674 pudiera ser el Cancionero de romances sin año, ya que no recoge la "Exclamación y querella de la gobernación". Desde finales del siglo XIX, cuando empezaron a publicarse los estudios sobre el romancero de personalidades del calibre de Wolf, Ticknor y, sobre todo Menéndez Pidal, hasta nuestros días, siempre se ha subrayado que Nucio se sirvió de pliegos sueltos a la hora de recopilar su obra. Esta idea se ha consolidado como norma, sobre todo debido a que hasta hoy no parece haber ningún caso seguro que demuestre lo contrario. Sin embargo, considero que, a pesar de que el encabezamiento de de 
RMND 674 apunte a lo opuesto, la posibilidad de que la recopilació de Nucio haya servido como fuente para el pliego no es una hipótesis a descartar ${ }^{21}$.

A todo esto habría que añadir un cotejo de los dos pliegos sueltos: RMND 674 y RMND 673. El mero hecho de que salieran de la misma imprenta con una diferencia de aproximadamente veinte años y de que presenten exactamente las mismas obras en el mismo orden, me hace suponer que, con gran probabilidad, el pliego suelto más antiguo, RMND 674, haya servido como modelo al más reciente RMND 673, además considerando que

[Felipe de Junta] para afianzar el negocio recurrió a una estrategia editorial conservadora, fatigando las prensas con ediciones reiteradas de los títulos del surtido tradicional del taller, desde los trataditos utilitarios de albeitería de Francisco de la Reina y de sanidad popular como el Thesoro de pobres hasta los consabidos pliegos de romances. ${ }^{22}$

Esta parece ser la hipótesis más realista. Sin embargo, el cotejo de los dos pliegos y Csa parece más bien afianzar la relación entre RMND 674 y el Cancionero de romances $\sin$ año, y presentar una serie de interrogantes sobre la posible derivación de RMND 673 a partir de RMND 674, abriendo así la posibilidad de la existencia de otro testimonio más o de una posible fuente oral para RMND 673.

Veamos las variantes de los tres testimonios, (como siempre omito las de lengua, las ortográficas y los despistes de cajista, del tipo ha mando por ha mandado):

1. Romance: "Don Rodrigo rey de España". -v. 16 qu[e]brar RMND 674 Csa: quitar RMND 673

En los versos 15-16 del romance se puede leer "El rey no puso el candado / mas todos los fue a quebrar/quitar". La lectura de RMND 673 mantiene la correlación poner (puso)/ quitar. En:

- v. 24 tiene RMND 674 Csa: ha de RMND 673

La variante que presenta RMND 673 es preferible. Mientras que:

- v. 27 nueva $R M N D 674$ Csa: nueve RMND 673

La lectio que nos transmite RMND 673 es claramente una errata de cajista.

- v. 30 menear RMND 674 Csa: remediar RMND 673

En todos estos ejemplos las variantes del pliego más antiguo coinciden con las del Cancionero de romances sin año evidenciando la relación que se debe de dar entre estos dos testimonios, como ya señalé anteriormente.

Las variantes que presentan los versos 16,24 y 30 solo se explican si RMND 673 tenía en la memoria otra versión oral o a la vista otra versión escrita subrayando

${ }^{21}$ De hecho, G. Ticknor (1851-1856), v. 1, p. 133 es el único que apunta la derivación de los romanceros de los pliego sueltos desmentido por R. Menéndez Pidal en su edición del Cancionero de romances impreso en Amberes sin año (1945), p. VII.

${ }^{22}$ M. Fernández Valladares (2005), p. 176. 
de este modo que RMND 673 tuvo que manejar una fuente distinta con respecto a RMND 674 y a Csa. En varias ocasiones, Di Stefano y Garvin han subrayado que las variantes que presentan los romances transmitidos a través de pliegos sueltos se han producido dentro de los talleres de imprenta y Garvin, yendo más allá, sostiene que

[...] las variantes que aparecen en los pliegos pueden explicarse sin necesidad de recurrir a la tradición oral ya que en mi opinión son variantes que, por diversos motivos, surgen a lo largo del proceso de copia de impreso a impreso y no representan un estadio en la evolución oral del romancero. ${ }^{23}$

Seguimos con el segundo romance, "Las huestes de don Rodrigo", que es idéntico en los dos pliegos, ya que no presenta variantes relevantes.

El romance "Ya de sale de la priessa" muestra:

- v. 16 un capitán RMND 674 RMND 673: un su capitán Csa

honrrado RMND 674 Csa: muy honrrado RMND 673

La variante de Csa con el posesivo precedido por el artículo es lingüísticamente más arcaizante que la lectio de los dos pliegos sueltos. RMND 673 restablece el verso de ocho sílabas introduciendo el adverbio muy mientras que el verso de RMND 674 resulta hipométrico. En:

- v. 19 halla $R M N D 674$ Csa: hallava RMND 673

la variante de RMND 673 es hipermétrica.

- v. 38 cayó tendida en su estrado RMND 674 Csa: allá cayó de su estado RMND 673

- v. 68 allá en lo más apartado RMND 674 Csa: allá arriba en lo más alto $R M N D 673$

En el caso de este romance también las variantes subrayan una vez más la relación que se da entre RMND 674 y Csa en contraposición con RMND 673 que, sobre todo en el caso de los versos 38 y 68 , se aparta notablemente de los otros dos testimonios. Las variantes de los versos que acabo de mencionar no excluyen, desde mi punto de vista, tan tajantemente como afirma Garvin, la influencia de la oralidad. Ciertamente pudo haber existido una fuente escrita, hoy perdida, transmisora de las variantes en cuestión, pero no descartaría por completo la posibilidad de que la transmisión oral de este romance haya sido la causa de las variantes entre los pliegos.

En el último romance de la serie: Romance: "Después que el rey don Rodrigo".

- v. 60 yo soy el que rey RMND 674 : yo soy que rey Csa RMND 673

- v. 61 vengo me hazer $R M N D 674$ : vengo a hazer Csa RMND 673

En:

- v. 75 fue $R M N D 674$ : fuele Csa RMND 673

La variante que presenta RMND 674 es hipométrica.

- v. 87 mandó $R M N D 674$ Csa : manda RMND 673

- v. 102 a ver ya si muerto avía $R M N D 674$ Csa : a ver si muerto sería RMND 673

${ }^{23}$ G. Di Stefano (2000) y M. Garvin (2007), p. 53. 
- v. 111 fue $R M N D 674$ Csa : fuera RMND 673

A pesar de que en varias ocasiones en este poema Csa parece aproximarse más a RMND 673 que a RMND 674 no considero que estos ejemplos sean suficientes para refutar del todo cuanto he expuesto hasta ahora, o sea, la posibilidad de que RMND 674 y el Cancionero estén más estrechamente vinculados que los dos pliegos sueltos entre sí y que posiblemente RMND 673 no utilizó como fuente directa RMND 674, sino otra distinta. Además, consideremos la variante del verso 102. Ambas variantes implican una diferencia de sentido, ya que la forma con ser indica un estado. No obstante, esa forma, aunque se perpetúa hasta el siglo XVII, no está muy generalizada desde el siglo XV. Parece improbable, por tanto, que un cajista de 1565-1570, que leería "muerto avía" decidiera sustituir esa forma tan habitual por otra menos frecuente, salvo que tuviera a la vista o en la memoria otra versión donde figurara "muerto sería" 24 .

Inevitablemente hay que suponer entonces que RMND 674 y RMND 673 manejaron fuentes diferentes, al menos en lo que concierne a los romances, y no excluyo que la fuente de RMND 673 pudiera ser una huella de la tradición oral del romancero en la memoria del tipógrafo.

En el caso específico de estos dos pliegos, Garvin propone el siguiente stemma ${ }^{25}$ :

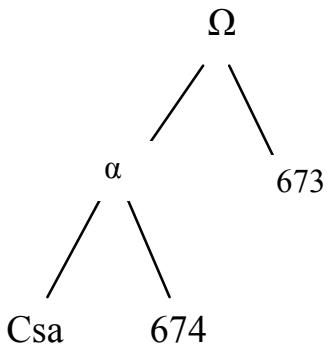

Creo necesario señalar que este stemma solo refleja una de las hipótesis posibles, ya que en él RMND 673 aparece más cercano a su modelo que RMND 674 y se hacen derivar el Cancionero y el pliego RMND 674 del mismo antecedente, excluyendo de esta manera la posibilidad de que la recopilación de Nucio haya sido la fuente del pliego burgalés más antiguo. Tampoco descartaría por completo que las variantes de los romances presentes en RMND 673 con respecto a RMND 674 no

\footnotetext{
${ }^{24}$ Véase a este propósito el capítulo sobre el "Subsitema de tiempos compuesto con ser" en I. Andrés-Suárez (1994).

${ }^{25}$ M. Garvin (2007), p. 182.
} 
dependan de una transmisión cruzada. El primero pudo haber tenido delante RMND 674 e introducir diferentes a partir de otra versión que tenía en la memoria.

Sin embargo, al analizar el poema que cierra los dos pliegos, "La exclamación y querella de la gobernación" de Gómez Manrique, sí parece que ambos pliegos están estrechamente vinculados y que el más temprano de ellos (RMND 674) haya servido como modelo para el segundo. Ambos imprimen diecisiete coplas de las dieciocho originarias del poema $\mathrm{y}$, excluyendo variantes gráficas y de lengua -introducidas con casi total seguridad por el cajista-, las únicas variantes presentes entre los dos son:

- v. 56 remunerados RMND 674: remunerado RMND 673

Se trata, con toda seguridad, de una errata introducida o por el cajista, que olvidó colocar la $s$ del plural en su componedor, o causada por la caída del tipo de la $s$.

- v. 79 los reinos sin buenos reyes $R M N D$ 674: los reyes sin buenos reyes $R M N D 673$

Aquí se equivoca claramente RMND 673, influido por la segunda mitad del verso. Es un error típico de copia. Lo mismo ocurre en:

- v. 102 guerrean $R M N D$ 674: pelean RMND 673

RMND 673, influido por la rima al v. 104 "por sendos onbres pelean", repite el mismo verbo.

Mientras que en:

- v. 34 breve RMND 674: muy breve RMND 673

RMND 673 introduce el adverbio rompiendo el verso octosílabo, lo mismo en:

- v. 128 hermosa RMND 674: la hermosa RMND 673

con la introducción del artículo.

En todos estos ejemplos, el pliego más tardío, RMND 673, presenta errores frente al otro, RMND 674, hecho que afianza la hipótesis de que el más temprano de los dos (RMND 674) haya servido como modelo para RMND 673 en el caso del poema manriqueño, y es lógico pensarlo dada además la precedencia cronológica. La única variante que se da entre RMND 674 con respecto a RMND 673, que lee con todos los demás testimonios, es:

- v. 142 receles $R M N D$ 674: recelo $R M N D 673$

Se trata de una errata accidental de RMND 674 que bien pudo corregir RMND 673 percatándose de la ruptura de la rima con el v. 136 "auran de venir al suelo".

Para concluir, resumiendo los resultados del cotejo de los dos pliegos sueltos burgaleses y del Cancionero de romances sin año, resulta lo siguiente:

- Con mucha probabilidad, los cuatro romances del ciclo del rey don Rodrigo y el poema de Gómez Manrique no fueron impresos en el mismo pliego suelto de manera casual. La relación temática que se da entre las cinco obras tiene que haber influido para que alguien, fuera o dentro del taller burgalés, deliberadamente decidiera reunirlas en este preciso orden para su impresión.

- El poema de Gómez Manrique es idéntico en los dos pliegos sueltos. A su vez, la "Exclamación y querella de la gobernación" no se recoge en el Csa, ya que en él solo se incluyen romances. 
- Por lo que concierne al poema manriqueño, Juan de Junta tuvo que servirse de una edición del Cancionero General de Hernando del Castillo posterior a 1511 para la impresión de RMND 674.

- Los romances contenidos en RMND 674 aproximan el pliego más al Csa, mientras que las lecturas de RMND 673 se apartan notablemente de los dos testimonios. Esto me hace suponer que puede que RMND 673 tuviera otra fuente, oral o escrita, a la hora de recopilar estos romances.

- En el caso de las fuentes de los cuatro romances, no hay elementos decisivos para afirmar nada con absoluta certeza. La hipótesis más verosímil es que una edición anterior de RMND 674 haya servido como fuente para Csa y RMND 674 como se ha venido afirmando desde principios del siglo pasado, pero no considero imposible, basándome principalmente en las rúbricas y en algunas variantes que RMND 674 haya copiado Csa.

\section{OBRAS CITADAS}

ANDRÉS-SUÁREZ, Irene: El verbo español. Sistemas medievales y sistema clásico, Madrid, Gredos, 1994.

BELTRÁN, Viçent: "Imprenta antigua, pliegos poéticos, cultura popular (-1516)", en La literatura popular impresa en España y en la América colonial. Formas \& temas, géneros, funciones, difusión, historia y teoría, dirigido por Pedro M. Cátedra, ed. al cuidado de Eva Belén Carro Carbajal [et al.], Salamanca, Seminario de Estudios Medievales y Renacentistas, 2006, pp. 363-379.

Cancionero de romances impreso en Amberes sin año, ed. facsímil con una introducción por R. Menéndez Pidal, Madrid, s. n., 1945, (Imp. Julián Santiago Rodríguez).

Cancionero general recopilado por Hernando del Castillo, introducción bibliográfica, índices y apéndices por Antonio Rodríguez-Moñino, Madrid, Real Academia Española, 1958.

Di StEFAnO, Giuseppe: "Il pliego suelto cinquecentesco e il Romancero", en Studi di filologia romanza offerti a Silvio Pellegrini, Liviana Editrice, Padova, 1971, pp. 111-143.

Di STEFANO, Giuseppe: "La tradizione orale e scritta dei romances. Situazioni e problemi", en Oralitá e scrittura nel sistema letterario, Roma, Bulzoni, 1982, pp. 205-225.

Di STEFANO, Giuseppe: "El pliego suelto: del lenguaje a la página", en Imprenta y crítica textual en el siglo de oro, Centro para la Edición de los Clásicos Españoles, Valladolid, 2000, pp. 171-185.

El Romancero, estudio, notas y comentarios de texto por Giuseppe di Stefano, Madrid, Narcea, 1983. 
FERNÁNDEZ VALLADARES, Mercedes: La imprenta en Burgos (1501-1600), Madrid, Arco Libros, 2005.

GARVIN BARBA, Mario: "Sobre sociología de la edición: el orden del Cancionero de romances (s.a. y 1550)", en La literatura popular impresa en España y en la América colonial. Formas y temas, géneros, funciones, difusión, historia y teoría, dirigido por Pedro M. Cátedra, edición al cuidado de Eva Belén Carro Carbajal [et al.], Salamanca, Seminario de Estudios Medievales y Renacentistas, 2006, pp. 491-502.

GARVIN BARBA, Mario: Scripta manent. Hacia una edición crítica del romancero impreso, Madrid, Iberoamericana, Frankfurt am Main, Vervuert, 2007.

INFANTES, Víctor: "Los pliegos sueltos poéticos: constitución tipográfica y contenido literario (1482-1600)", en El libro antiguo español. Actas del primer Coloquio Internacional (Madrid, 18 al 20 de diciembre de 1986), al cuidado de María Luisa López-Vidriero y Pedro M. Cátedra, Publicaciones de la universidad de Salamanca, Biblioteca Nacional de Madrid, Sociedad Española de Historia del Libro, 1988, pp. 237-248.

INFANTES, Víctor: "Edición, literatura y realeza, apuntes sobre los pliegos poéticos incunables", en Literatura hispánica, Reyes Católicos y Descubrimiento (Actas del Congreso Internacional sobre Literatura hispánica en la época de los Reyes Católicos y el Descubrimiento), Manuel Criado de Val Ed., Barcelona, PPU, 1989, pp. 85-98.

MANRIQUE, Gómez: Cancionero, Edición de Francisco Vidal González, Madrid, Cátedra, 2003.

MENÉNDEZ PIDAL, Ramón: Romancero hispánico (hispano-portugués, americano y sefardi). Teoria e historia, tomo I, Madrid, Espasa-Calpe, 1953.

NORTON, F. J., WILSON, Edward M.: Two Spanish verse chap-books. Romançe de Amadis (c. 1515-19). Juyzio hallado y trobado (c. 1510). A facsimile edition with bibliographical and textual studies, London, Cambridge University Press, 1969.

PUERTO MORO, Laura: "El universo del pliego poético postincunable (del despegue de la literatura popular impresa en castellano)", eHumanista, 21 (2012), pp. 257-304.

RODRÍGUEZ-MOÑINO, Antonio: Nuevo diccionario bibliográfico de pliegos sueltos poéticos, edición corregida y actualizada por Arthur L.-F Askins \& Víctor Infantes, Madrid, Castalia, 1997.

Romancero, ed. de Pedro M. Piñero, Madrid, Biblioteca Nueva, 2004.

Romancero tradicional de las lenguas hispánicas (español-portugués-catalánsefardí). 1. Romanceros del rey Rodrigo y de Bernardo del Carpio. Colección de textos y notas de María Goyri y Ramón Menéndez Pidal, Madrid, Gredos, 1957.

SÁnCHEZ-PRIETO BORJA, Pedro: Cómo editar los textos medievales. Criterios para su presentación gráfica, Madrid, Arco Libros, 1998.

TICKNOR, George: Historia de la literatura española, traducida al castellano con adiciones y notas criticas por Pascual de Gayangos y Enrique de Vedia, s.l., s.n., 1851-1856, (Madrid, Imp. de La Publicidad). 